The Korean Journal of Parasitology

Vol. 38, No. 1, 45-48, March 2000

Brief Communication

\title{
Isozyme electrophoresis patterns of the liver fluke, Clonorchis sinensis from Kimhae, Korea and from Shenyang, China
}

\author{
Gab-Man PARK ${ }^{1)}$, Tai-Soon YONG ${ }^{1) *}$, Kyung-il IM ${ }^{1)}$ and Kyu-Je LEE ${ }^{2)}$ \\ Department of Parasitology and Institute of Tropical Medicine ${ }^{1)}$, \\ Yonsei University College of Medicine, Seoul 120-752, and Department of Parasitology2), \\ Yonsei University Wonju College of Medicine, Wonju 220-701, Korea
}

\begin{abstract}
An enzyme analysis of the liver fluke, Clonorchis sinensis from Kimhae, Korea and from Shenyang, China was conducted using a horizontal starch gel electrophoresis in order to elucidate their genetic relationships. A total of eight enzymes was employed from two different kinds of buffer systems. Two loci from each enzyme of aconitase and esterase $(\alpha-\mathrm{Na}$ and $\beta-\mathrm{Na})$; and only one locus each from six enzymes, glucose-6-phosphate dehydrogenase (G6PD), $\alpha$-glycerophosphate dehydrogenase (GPD), 3-hydroxybutyrate dehydrogenase (HBDH), malate dehydrogenase (MDH), phosphoglucose isomerase (PGI), and phosphoglucomutase (PGM) were detected. Most of loci in two populations of $C$. sinensis showed homozygous monomorphic banding patterns and one of them, GPD was specific as genetic markers between two different populations. However, esterase $(\alpha-\mathrm{Na})$, GPD, HBDH and PGI loci showed polymorphic banding patterns. Two populations of $C$. sinensis were more closely clustered within the range of genetic identity value of 0.9981.0. In summarizing the above results, two populations of $C$. sinensis employed in this study showed mostly monomorphic enzyme protein banding patterns, and genetic differences specific between two populations.
\end{abstract}

Key words: Clonorchis sinensis, isozyme, electrophoresis, genetic identity, China, Korea

Clonorchis sinensis, the Chinese or the oriental liver fluke, is an important human parasite and is widely distributed in the southern parts of Korea, China, Taiwan, and in the northern part of Vietnam (Rim, 1990). Clonorchiasis is one of the most important endemic diseases persisting in Korea. A few field biologists/scientists have conducted

- Received 17 November 1999, accepted after revision 15 February 2000.

- This study was supported by the research grant for the development of Health and Medical Technology (HMP-97-M-2-0015), Ministry of Health and Welfare, Korea

*Corresponding author (e-mail: tsyong212@ yumc.yonsei.ac.kr) studies of C. sinensis on its biology, epidemiology, pathology, clinical symptoms as well as the treatment (Rim et al., 1973; Chu et al., 1982; Kim et al., 1982; Cho et al., 1983).

Enzyme electrophoresis and restriction site analyses are applicable to most of the studies on intraspecific variations. These methods remain to be popular choice, although DNA sequencing may be employed to resolve seemingly sophisticated problems determining a specific variation (Selander, 1976; Vrijenhoek, 1978; Chance and Walton, 1982; Hillis and Moritz, 1990; Andrews and Chilton, 1999). Recently, gel electrophoresis has been widely used in trematode systematics (Agatsuma and Habe, 1986; Woodruff et al., 
1987; Agatsuma et al., 1994; Hope et al., 1995). The present work was carried out in order to elucidate the genetic relationships of C. sinensis existing in Korea and China.

Adult flukes used in this study were obtained from rabbits that were experimentally infected with $C$. sinensis metacercariae. Metacercariae were recovered from the fish, Pseudorasbora parva, caught from Kimhae in Kyungsangnam-do, Korea and from Shenyang, Liaoning Province, China. The rabbits were then sacrificed about 5 mo post infection. Adult parasites were homogenized and centrifuged at $12,000 \mathrm{rpm}$, and the aliquotes of supernatants were subjected to starch gel electrophoresis. Eight enzymes from two different kinds of buffer systems (TC-I and TCII) examined in this study were as follow: Aconitase-I, II (ACO I, II), Esterase (EST $\alpha$-Na, $\beta$-Na), Glucose-6-phosphate dehydrogenase (G6PD), $\alpha$-Glycerophosphate dehydrogenase (GPD), 3-Hydroxybutyrate dehydrogenase $(\mathrm{HBDH})$, Malate dehydrogenase $(\mathrm{MDH})$, Phosphoglucose isomerase (PGI), and Phosphoglucomutase (PGM) (Table 1). In order to discuss the relative phylogenetic relationships among the two populations of Clonorchis species, the normalized identity of the gene and the standard genetic distance were used (Nei, 1972). The genetic identity is a measure of the proportion of the genes that are identical in two populations, and the genetic distance is a measure of the number of allelic substitutions per locus that have occurred during the separate evolution of two populations or species.

Eleven loci were obtained from eight enzymes. Examples of zymograms are shown in Fig. 1. Five out of 11 loci were polymorphic ((EST ( $\alpha$-Na), GPD, HBDH, MDH, PGI)), and the number of alleles per polymorphic locus varied from two to three. A single monomorphic band of ACO-I, II, EST $\beta$-Na, G6PDH, MDH-I, II, PGM was observed in all the subjected individuals. Monomorphic double bands of MDH-I showed strong and fast migration band. MDH-II was slow and the activity was poor than MDH-I. $\alpha$-Glycerophosphate dehydrogenase was composed of three bands. This locus was population-specific. The slowest band was demonstrated only in the Chinese population. The fast and intermediate bands were observed in Korean population only. In other words, the enzyme GPD in Korean population showed typical monomeric banding patterns, whereas those in Chinese population were monomorphic without any variation. This result indicates that the monomorphic patterns of GPD in Chinese population are supported by genetic stability in the populations. After gel electrophoresis, EST $(\alpha-\mathrm{Na})$ showed three different bands. The intermediate band was common in all the individuals between two populations. The slow moving band occurred for the Korean population. The average heterozygosity frequency of each Korean and Chinese population was 0.146 and 0.078 , respectively (Table 2). Accordingly, the genetic variance of Korean population was little higher than the Chinese population, and the average heterozygosity frequency of two populations was 0.112 . This value was above conspecific level of Avise's suggestion (1974). Clonorchis sinensis found both in Korea and China are so similar in their phenotypic distributions and in

Table 1. Eight enzymes assayed in two different buffer systems in this study

\begin{tabular}{lccc}
\hline \hline \multicolumn{1}{c}{ Enzymes (EC Number) } & No. loci scored & Abbreviation & Buffer system \\
\hline Aconitase (4.2.1.3) & 2 & ACO & TC-Ia) \\
Esterase (3.1.1.1.) & 2 & EST & TC-II \\
Glucose-6-phosphate dehydrogenase (1.1.1.49) & 1 & G6PDH & TC-II \\
$\alpha$-Glycerophosphate dehydrogenanse (1.1.1.8) & 1 & GPD & TC-II \\
3-Hydroxybutyrate dehydrogenase (3.1.1.31) & 1 & HBDH & TC-II \\
Malate dehydrogenease (1.1.1.37) & 2 & MDH & TC-II \\
Phosphoglucose isomerase (5.3.1.9) & 1 & PGI & TC-II \\
Phosphoglucomutase (2.7.5.1) & 1 & PGM & TC-II \\
\hline
\end{tabular}

a)TC-I: Tris/HCl-0.2 M-pH 8.0; b)TC-II: Tris/HCl-0.5 M-pH 8.0 


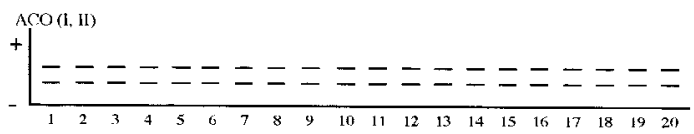

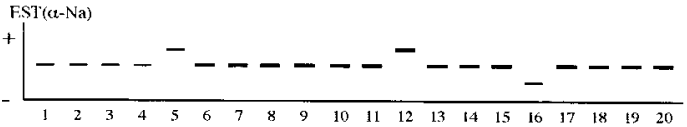
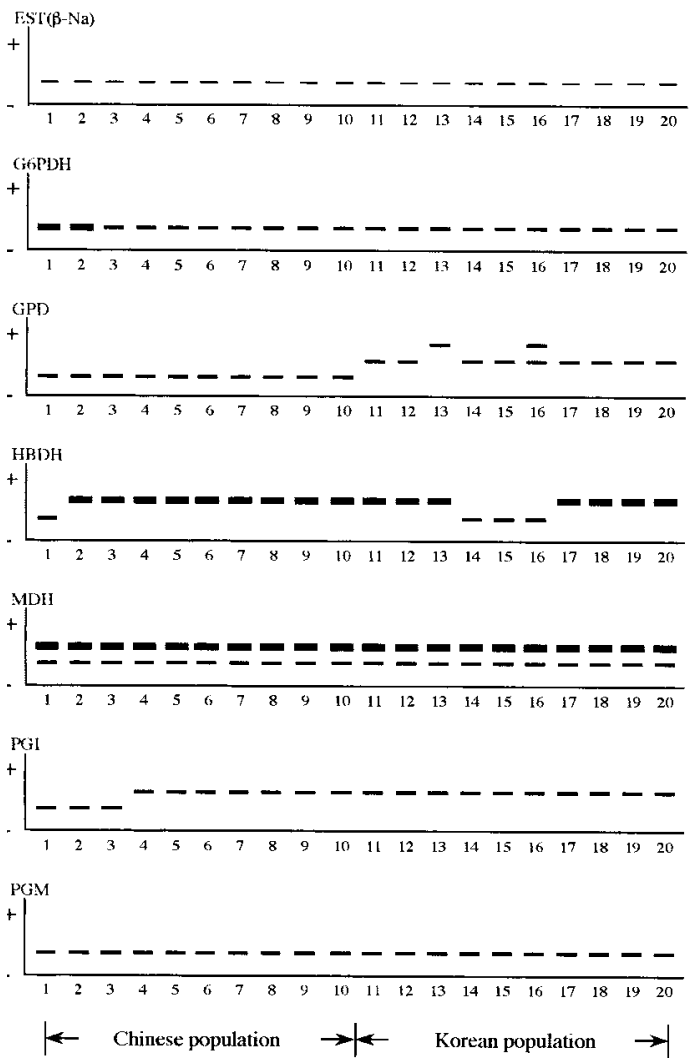

Fig. 1. Zymograms of eight enzymes of liver fluke, Clonorchis sinensis from Kimhae, Korea and from Shenyang, China.

their allele frequencies and the isozymes band patterns, that they are indistinguishable. Most geographically separated populations share the same alleles at monomorphic and polymorphic loci, and at similar frequencies in the latter (Ferguson, 1980). The genetic identity values of sibling species by isozyme electrophoresis patterns are $0.626(0.539$ 0.777 at invertebrate) and $0.567(0.300-0.833$ at invertebrate) in distinct species reported by Ferguson (1980). In this study, genetic identity of two populations was 0.998-1.0. Consequently, from this point of view, C. sinensis
Table 2. Allele frequencies for two populations of Clonorchis sinensis from Kimhae in Korea and from Shenyang in China

\begin{tabular}{|c|c|c|c|}
\hline \multirow[b]{2}{*}{ Locus } & \multirow[b]{2}{*}{ Allozyme } & \multicolumn{2}{|c|}{ Population } \\
\hline & & China & Korea \\
\hline \multirow[t]{2}{*}{ ACO-I } & $\mathrm{a}$ & 1.0 & 1.0 \\
\hline & $\mathrm{H}^{\mathrm{a})}$ & 0 & 0 \\
\hline \multirow[t]{2}{*}{ ACO-II } & $\mathrm{a}$ & 1.0 & 1.0 \\
\hline & $\mathrm{H}$ & 0 & 0 \\
\hline \multirow[t]{4}{*}{$\operatorname{EST}(\alpha-\mathrm{Na})$} & $\mathrm{a}$ & 0.1 & 0.1 \\
\hline & b & 0.9 & 0.8 \\
\hline & $\mathrm{c}$ & & 0.1 \\
\hline & $\mathrm{H}$ & 0.28 & 0.34 \\
\hline \multirow[t]{2}{*}{$\operatorname{EST}(\beta-\mathrm{Na})$} & $\mathrm{a}$ & 1.0 & 1.0 \\
\hline & $\mathrm{H}$ & 0 & 0 \\
\hline \multirow[t]{4}{*}{ GPD } & $\mathrm{a}$ & 1.0 & \\
\hline & $\mathrm{b}$ & & 0.85 \\
\hline & $\mathrm{c}$ & & 0.15 \\
\hline & $\mathrm{H}$ & 0 & 0.26 \\
\hline \multirow[t]{2}{*}{ 6GPDH } & $\mathrm{a}$ & 1.0 & 1.0 \\
\hline & $\mathrm{H}$ & 0 & 0 \\
\hline \multirow[t]{3}{*}{$\mathrm{HBDH}$} & $\mathrm{a}$ & 0.9 & 0.4 \\
\hline & $\mathrm{b}$ & 0.1 & 0.6 \\
\hline & $\mathrm{H}$ & 0.18 & 0.48 \\
\hline \multirow[t]{2}{*}{ MDH-I } & $\mathrm{a}$ & 1.0 & 1.0 \\
\hline & $\mathrm{H}$ & 0 & 0 \\
\hline \multirow[t]{2}{*}{ MDH-II } & $\mathrm{a}$ & 1.0 & 1.0 \\
\hline & $\mathrm{H}$ & 0 & 0 \\
\hline \multirow[t]{3}{*}{ PGI $=(G P I)$} & $\mathrm{a}$ & 0.7 & 1.0 \\
\hline & & 0.3 & \\
\hline & $\mathrm{H}$ & 0.42 & 0 \\
\hline \multirow[t]{2}{*}{ PGM } & $\mathrm{a}$ & 1.0 & 1.0 \\
\hline & $\mathrm{H}$ & 0 & 0 \\
\hline \multicolumn{2}{|c|}{ Heterozygosity frequency } & 0.078 & 0.146 \\
\hline \multirow{2}{*}{\multicolumn{2}{|c|}{ No. of mean allele }} & $14 / 11$ & $15 / 11$ \\
\hline & & $(1.27)$ & $(1.36)$ \\
\hline
\end{tabular}

a)Heterozygosity per locus

collected from Kimhae in Korea and from Shenyang in China showed a little variation and were suggested to be identical species.

\section{REFERENCES}

Agatsuma T, Habe S (1986) Genetic variability and differentiation of natural populations in three Japanese lung flukes, Paragonimus ohirai, Paragonimus iloktsuenensis and Paragonimus sadoensis (Digenea: Troglotrematidae). J Parasitol 72: 417-433. 
Agatsuma T, Terasaki K, Yang L, Blair D (1994) Genetic variation in the triploids of Japanese Fasciola species, and relationships with other species in the genus. $J$ Helminthol 68: 181186.

Andrews RH, Chilton NB (1999) Multilocus enzyme electrophoresis: a valuable technique for providing answers to problems in parasite systematics. Int $J$ Parasitol 29: 213-253.

Avise JC (1974) Systematic value of electrophoretic data. Syst Zool 23: 465-481.

Chance ML, Walton BC (1982) Biochemical characterization of Leishmania. Proceedings of Workshop held at the Pan American Health Organization, Washington, D.C., UNDP/ WORLD BANK/WHO.

Cho SY, Song KY, Rah BJ (1983) Lipofuscin pigment in adult Clonorchis sinensis. Korean $J$ Parasitol 21: 32-39.

Chu DS, Jeong KH, Rim HJ (1982) Studies on the blood intake activity by Clonorchis sinensis in experimental animals. Korea Univ Med $J$ 19: 71-80 (in Korean).

Ferguson A (1980) Biochemical systematics and evolution. pp1-194. John Willey and Sons, New York \& Toronto, USA.

Hillis DM, Moritz C (1990) An overview of applications of molecular systematics. In Molecular systematics, Hillis DM and Moritz C (ed.) pp502-515. Sinauer Associates Inc.,
Sunderland, Massachusetts USA.

Hope M, Foley DH, McManus DP (1995) Electrophoretically-detected allozyme variation reveals only moderate differentiation between Chinese and Philippine Schistosoma japonicum. Acta Trop 60: 101-108.

Kim MS, Lee JS, Rim HJ (1982) Studies on the clinical aspects of clonorchiasis in Korea. Korea Univ Med $J$ 19: 107-121 (in Korean).

Nei M (1972) Genetic distance between populations. Am Natl 106: 283-292.

Rim HJ (1990) Clonorchiasis in Korea. Korean $J$ Parasitol 28(suppl.): 63-78.

Rim HJ, Lee SK, Seo BS (1973) Studies on the epidemiology and clinical aspects on clonorchiasis in Korea. New Med $J$ 16: 81-91 (in Korean).

Selander RK (1976) Genetic variation in natural population. In Molecular evolution. pp21-45. Sinauer Associates Inc. Sunderland, Massachusetts, USA.

Vrijenhoek RC (1978) Genetic differentiation among larval nematodes infecting fishes. $J$ Parasitol 64: 790-798.

Woodruff DS, Merenlender AM, Upatham ES, Viyanant V (1987) Genetic variation and differentiation of three Schistosoma species from the Philippines, Loas, and peninsula Malayasia. Am J Trop Med Hyg 36: 345-354. 